Fecha de recepción: marzo 2008 Fecha de aceptación: abril 2008 Versión final: diciembre 2008

\section{Los nuevos caminos de la comunicación: las experiencias multisensoriales}

Allan McCrea Steele ${ }^{(*)}$

${ }^{(*)}$ Licenciado en Relaciones Públicas de la Universidad Argentina de la Empresa (UADE). Es Presidente en Edelman América del Sur y Presidente \& CEO en Edelman Argentina

Resumen: El presente trabajo realiza un abordaje de lo que hoy se denomina Comunicación Multisensorial, en la cual la creatividad del lenguaje humano adquiere una relevancia aún mayor como vehículo generador de nuevos contenidos por llegar al consumidor. Describe el escenario hacia donde ha ido evolucionando la comunicación -esquema en el que ya no son suficientes los modelos ni los canales tradicionales- con el objetivo de identificar oportunidades, capitalizar beneficios y alcanzar de manera efectiva a las audiencias en las cuales las compañías quieren posicionarse institucionalmente, o hacia donde las marcas necesitan ir para lograr 'vender' sus productos. La comunicación $360^{\circ}$ y la visión a largo plazo que ofrecen las Relaciones Públicas, permitirá a las marcas encontrar las mejores situaciones para encontrarse con sus consumidores en este contexto de los sentidos y experiencias.

Palabras claves: Brand Experience - Comunicación 360 - Comunicación con los Clientes - comunicación corporativa - Comunicación de Marketing - comunicación empresaria - comunicación institucional - Comunicación los Consumidores - Comunicación Multisensorial - Comunicaciones Integradas - gestión comunicacional - imagen corporativa - organización - planes de comunicación - públicos - Relaciones Públicas.

[Resúmenes en inglés y portugués en la página 143]

\title{
Los nuevos caminos de la comunicación: las experiencias multisensoriales
}

A veces nos preguntamos por qué un ser humano no puede vivir en soledad. Quizás la respuesta se pueda encontrar en un sinfín de canciones de diversos autores e idiomas o también en gran cantidad de libros teóricos que cuentan que la comunicación existe porque hay un emisor que emite un mensaje y un receptor que lo recibe según su universo de percepciones, con la participación de otros elementos no menos importantes como el código, el ruido que afectará al mensaje, el canal por el cual se emite el mensaje y la tan conocida retroalimentación, o más conocida como feedback en palabras sajonas, de parte del receptor.

Sin embargo, lo más importante aquí es destacar que los seres humanos nos comunicamos porque nacimos para vivir en relación con otros, ya que tenemos el instinto natural y la necesidad de transmitir ideas, proyectos, pensamientos, sensaciones, sentimientos y tantas otras cosas más que nos permitan relacionarnos entre nosotros.

La comunicación tiene un origen histórico de millones de años atrás. Desde su surgimiento, el hombre 
ha buscado las más diversas formas de comunicar sus ideas y pensamientos. En la era prehistórica, los trogloditas, además de comunicarse por medio del lenguaje verbal y no verbal, lo hacían también a través de dibujos petrográficos sobre salientes de roca en las cavernas, pintando los cráneos de osos o también los caparazones de tortugas.

Miles de años después, los faraones egipcios fueron los primeros en crear jeroglíficos y descubrir el material con el cual se podían dejar impresos gran cantidad de escritos de la época. Así, la llegada de la escritura, descriptiva y no alfabética en este caso, permitía que dos personas que hubieran leído el mismo material se encuentren conectadas y se 'comuniquen'.

Continuando a lo largo de la historia, la creación de la imprenta en los inicios del Renacimiento dio comienzo a cierta masificación de los libros de lectura en otras clases, más allá de la nobleza. A su vez, la creación de los medios de comunicación tradicionales como los diarios, la radio y la televisión sin dudas también han marcado fuertemente la historia de las comunicaciones.

Estos son sólo algunos ejemplos representativos, pero sin dudas que existen muchos otros casos que se pueden citar. De todas formas, aquí también es importante tener en cuenta que el ser humano no es el único ser vivo que se comunica de diversas formas, sino todo lo contrario; los animales han tenido, y aún tienen obviamente, diferentes formas de comunicarse, ya sea para transmitirle a otro par el surgimiento de alguna fuente de alimento, como así también con motivos de defensa propia o de su familia, para marcar su territorio o con fines de apareamiento entre las especies. Así es que en el reino animal existen diversas formas de señales de comunicación, que podríamos caracterizar brevemente de la siguiente manera:

- Señales químicas: surgen a través de la emisión de diversas sustancias químicas llamadas feromonas que vuelan a través del aire, afectando al sentido del olfato y del gusto. Así por ejemplo, la abeja reina produce una feromona especial que limita el desarrollo de los ovarios de las abejas obreras.

- Señales acústicas: se dan por medio de la transmisión de sonidos específicos que afectan al sentido de la audición, como suele suceder entre las ballenas que quieren comunicarse a grandes distancias.

- Señales visuales: generalmente consisten en movimientos bruscos, mayor coloración de determinadas partes del cuerpo del animal o inclusive en la producción de destellos luminosos en ciertos animales. Tan solo por mencionar algunos ejemplos podemos hablar de las mariposas que cambian su color para atraer a las hembras o ciertos tipos de bailes de algunas aves en momento de apareamiento.

- Señales táctiles: ocurren mediante el contacto a través de la piel o partes exteriores de los seres vivos, la vibración de ciertas partes del cuerpo, la generación de ondas en la superficie del agua o ciertos golpes sobre cuevas u otras superficies terrestres, llegando así a la comunicación táctil. Estos casos se da por ejemplo con los machos topos que golpean su cabeza contra las paredes de sus cuevas para comunicarse entre ellos.

Asimismo, existen algunas diferencias entre el lenguaje humano y el animal que no se debería de pasar por alto; el primero posee una estructura de doble articulación que el segundo no, es decir la comunicación humana está conformada por expresiones lingüísticas con contenido semántico y sonidos carentes de significado propio. Otra diferencia surge en el punto en que el lenguaje animal es innato e instintivo, surgiendo como reacción a estímulos externos, mientras que el lenguaje humano es creativo, ya que se aprende y combina permanentemente elementos preexistentes para generar nuevas formas de comunicación.

Más allá de estas diferencias lógicas, es importante resaltar cómo este entretejido de comunicaciones 
tanto humanas como animales permiten resaltar el valor de lo que hoy se llama comunicaciones multisensoriales y en las cuales la creatividad del lenguaje humano adquiere una relevancia aún mayor como vehículo generador de nuevos contenidos por llegar al consumidor. Al mismo tiempo, esto permite demostrar que a medida que el mundo ha ido evolucionando así lo ha hecho la comunicación.

Históricamente el modelo de comunicación, y particularmente el de las Relaciones Públicas, ha sido caracterizado dentro de los siguientes modelos por diversos autores como Grunig y Hunt en su libro Managing Public Relations (1984):

- Modelo Publicity/Agente de Prensa: basado en una comunicación unidireccional con el objetivo de contar acerca de una propaganda, con información incompleta, distorsionada o cierta a medias.

- Modelo de Información Pública: aquí solamente se persigue la difusión de información sin intención explícita de persuadir al receptor.

- Asimétrico Bidireccional: con una comunicación de doble vía se busca lograr la persuasión científica y se obtiene feedback del receptor del mensaje.

- Simétrico bidireccional: en este modelo ya se persigue otro tipo de objetivos más relacionados con la actualidad de la comunicación ya que se busca lograr una comprensión mutua.

En la actualidad hay una realidad que es ineludible y de la cual no podemos 'escapar', sino más bien aprovecharla y explotar al máximo sus beneficios: la comunicación está cambiando, rompiendo barreras que nunca imaginó poder romper, llegando a lugares que no imaginó llegar, utilizando medios que en otras épocas hubiesen sido considerados insólitos o carentes de cualquier utilidad. Es decir, este gran cambio en la comunicación está marcado porque ya no son suficientes los modelos ni los canales tradicionales de comunicación (como los diarios y revistas, la radio o la televisión), para alcanzar de manera efectiva a las audiencias a las cuales las compañías quieren llegar para posicionarse institucionalmente o hacia donde las marcas necesitan ir para lograr 'vender' sus productos.

Esta tendencia, que no se sabe aún cuánto tiempo durará dada la versatilidad de este mundo en el cual vivimos, nos lleva a pensar que si bien los medios tradicionales siguen siendo en la actualidad una parte fundamental en la comunicación, éstos necesitan complementarse indefectiblemente con otros medios no tradicionales (internet y otros medios digitales como por ejemplo la telefonía celular, la realización de acciones en la vía pública y eventos corporativos y de lanzamiento de productos, campañas de marketing directo, entre otras) que permitan llegar a sus audiencias a través de lo que venimos denominando Comunicación Multisensorial, es decir aquella comunicación a través de los 5 sentidos, en la cual el consumidor actúe, interactúe, converse, sienta, huela, vea y escuché activamente lo que la marca le ofrece como tal y pueda afianzar su vínculo con ella.

Y aquí es importante detenerse en la definición del concepto de marca y su valor real: una marca es todo aquello que integra las percepciones que el público tiene de una determinada organización y que permiten ofrecer un carácter distintivo frente a otras organizaciones; una marca es un aspiracional al cual determinado público quiere pertenecer por los valores y atributos que transmite; así, la marca como tal se ha convertido en el activo más importante de las más reconocidas empresas porque han mantenido a lo largo del tiempo una fuerte asociación con sus consumidores. Podemos mencionar algunos referentes como han sido Nike, Apple o Google, quienes han centralizado sus esfuerzos en generar una imagen de marca muy fuerte, con las particularidades respectivas de cada caso, y le han dado un gran valor a la opinión de sus consumidores y a la interacción con ellos, generando fuertes 
vínculos con las emociones de sus consumidores como muy pocas marcas han podido lograrlo a través de los años.

\section{Un mundo de percepciones}

En este mundo de percepciones en el cual vivimos, los sentidos son el mecanismo fisiológico que nos permiten poner en marcha este concepto de Comunicación Multisensorial hacia el cual deben dirigirse las marcas para motivar a sus audiencias a actuar; a medida que el cerebro humano recibe estímulos externos va conformando un entramado neural de mayor complejidad que son los que llevarán al consumidor a la toma de decisiones ante un nuevo estímulo externo, como puede ser la propuesta de una determinada marca o producto.

Diversos estudios han demostrado que la posibilidad de crear experiencias que generen nuevas y profundas sensaciones serán el valor agregado que tendrán las marcas para diferenciarse en este tan competitivo y saturado mercado comunicacional; ya que como se menciona anteriormente una persona siempre recuerda mejor algo que vivió en persona como experiencia propia que algo que solamente haya escuchado, le hayan contado o que simplemente haya tenido la posibilidad de verlo. Este cambio en las formas de acercarnos a nuestros consumidores, que se está acentuando en los últimos años, no trata de una tendencia local que esté sucediendo solamente en Argentina, sino que ha tenido su origen en los países de gran desarrollo económico y social como los EE.UU, Inglaterra, Francia, entre otros mercados europeos, y se ha ido esparciendo hacia otros países en desarrollo como México, Brasil y China llegando así, en forma gradual, a prácticamente 'todo' el mundo.

Los motivos por los cuales la comunicación ha ido cambiando han sido varios, y seguirá haciéndolo sin dudas, pero quizás podemos comenzar destacando los siguientes:

- La irrupción de nuevas tecnologías de la información; la denominada era digital o PR 2.0, donde el usuario adquiere una participación activa fundamental y en la cual ya no se habla de comunicación como tal, sino de una 'conversación' entre las marcas y sus audiencias. El usuario adquiere una relevancia mucho mayor que en los medios tradicionales dado que es parte activa del diálogo, dejando de lado su anonimato, retroalimentando a la marca de una manera mucho más dinámica e incentivándola a generar cambios y adaptaciones permanentes en su forma de comunicarse.

- La confianza de las personas en 'gente como uno' tal como lo refleja el estudio Edelman Trust Barometer 2008, la encuesta que se realiza todos los años a más de 3.700 líderes de opinión en 18 mercados. Este tipo de estudios demuestran el cambio en el paradigma de la comunicación alrededor de todo el mundo para la construcción de la reputación de las marcas, ya que los grupos de todas las edades confían más en expertos y personas como ellos mismos, es decir sus pares, a la hora de buscar información confiable. Es decir esto demuestra que debemos apuntar más a una comunicación en sentido horizontal que el sentido verticalista utilizado tradicionalmente.

- La saturación de mensajes a la cual está expuesta al consumidor; semanalmente las personas están expuestas a alrededor de 3.000 mensajes de comunicación que intentan lograr vender un producto o posicionar una empresa en nuestro universo de percepciones; las gigantografías en las autopistas, las promociones en vía pública, los pop-ups en las páginas que visitamos en internet, entre otros tantos y novedosos vehículos de comunicación que existen actualmente, hacen que la capacidad de atención del consumidor se vea reducida y donde deban resaltarse la creatividad de las marcas para llegar a su público potencial en el momento y lugar indicado y de la forma más impactante posible. 
- Un consumidor mucho más 'educado' y 'selecto'; como consecuencia de los puntos destacados anteriormente (la era digital, la confianza en gente 'como uno' y la saturación de mensajes), el consumidor se ha ido educando y culturizando sobre qué quiere 'oír', dónde, cómo, cuándo y con quién; obviamente esto no es sólo en el sentido literal de la palabra 'oír' sino también desde el punto de vista de lo que quiere ver, sentir, conocer, etc. Al consumidor actual le gusta diferenciarse y ser 'mimado' como único por su marca preferida; ser atendido como una persona única con sus gustos y preferencias únicas y diferentes a los de otras personas, ya que hoy ya no existen prácticamente los productos 'masivos'.

Así, para poder lograr una fidelización mayor hacia la marca se deben utilizar otro tipo de comunicaciones, ya no alcanza solamente con producir una publicidad creativa, publicar una nota de prensa en los medios de comunicación o contarles una linda historia; la comunicación debe estar segmentada por nichos mucho más específicos que la comunicación masiva tradicional; estos grupos deben contemplar un mix de diversas variables como la edad, el nivel socioeconómico, nivel educativo, realización de actividades deportivas y/o culturales, gustos personales, y así la lista podría extenderse tranquilamente. A mayor precisión en la definición de variables que permitan segmentar nuestro público, mayor será el éxito de las acciones que realicemos.

De esta forma, se busca que la relación marca-consumidor se de en el formato de experiencias que generen una fuerte asociación del público con su marca: y aquí es donde ésta, al momento de comunicarse, debe realizar diferentes acciones que generen sensaciones en el consumidor, apelando a los 5 sentidos del ser humano.

Volviendo a este nuevo paradigma de la comunicación a través de los sentidos, es importante hacer referencia a algunas definiciones que Martín Lindstrom (Brand Sense, 2005) ha mencionado sobre los sentidos con el modelo de la Marca de las 5 Dimensiones y algunos ejemplos aportados tanto desde su óptica como la de quién escribe:

- Visión: es considerada la más seductora de los sentidos, inclusive con el poder de persuadir a los consumidores más allá de la lógica; en diferentes pruebas de bebidas los consumidores creían que a colores fuertes, más dulce sería la bebida y las pruebas demostraron todo lo contrario, ya que a colores más fuertes las bebidas eran más ácidas. Desde otro punto de vista, un caso ejemplificador de posicionamiento histórico de marca enfocado fuertemente en la visión se da con Coca Cola, que a través de un uso consistente del color, una tipografía distintiva, el 'moño en movimiento', y el logo ha logrado establecer una imagen muy clara e imposible de confundir.

- Audición: así como el olfato está conectado a la memoria, los sonidos están vinculados al estado de ánimo de las personas; generan sentimientos y emociones positivas y negativas en igual medida. Por ejemplo, una película de amor sin música no tendrá el mismo efecto que una que esté acompañada por una canción melódica.

- Olfato: se trata del sentido más básico y directo; ya que no podemos no utilizarlo; las personas utilizamos el sentido del olfato más de 20.000 veces al día, dado que con cada inspiración que realizamos lo estamos utilizando. Estamos expuestos a miles de diferentes olores que la cantidad de letras que integran nuestro vocabulario no nos alcanzan para poder describirlo. Por ejemplo, es muy común que determinadas casas de ropa, especialmente las femeninas, utilicen determinadas fragancias para diferenciarse de sus competidores y atraer sus posibles consumidores; dado en un mercado donde esté tipo de detalles establece la diferencia para ser exitoso como marca.

- Tacto: este sentido que utilizamos a través de nuestra piel nos permite llegar a aquellos públicos que 
por infortunios de la vida han perdido su visión y/o su capacidad de audición. La piel es el órgano más extenso del cuerpo humano y por medio de ella estamos alertas al frío, al calor, al dolor, entre otras cosas. Un caso testigo es el de Samsung, una compañía que se ha enfocado en el diseño de sus productos como principal diferenciador frente a sus competidores. Además, esto se encuentra acompañado por sonidos representativos de la marca y por la utilización de un aroma específico que la identifica, sumando obviamente al impacto estético generado desde el punto de vista visual. Asimismo, la compañía posee en Nueva York un centro de experiencias que conjugan todos estos aspectos destacados de la comunicación multisensorial.

- Gusto: este sentido se conforma de estructuras especiales que poseemos en nuestras bocas llamadas yemas del gusto, con más de 10.000 concentradas especialmente en nuestras lenguas. Las yemas nos permitirán detectar los diferentes sabores de los alimentos que ingerimos. A su vez, este sentido forma una parte básica e integral de nuestras vidas como es el caso del olfato y son dos sentidos estrechamente vinculados, ya que muchas veces uno huele los sabores más que degustarlos. En síntesis, el gusto es el más débil de nuestros sentidos. La reconocida compañía Colgate es un claro ejemplo, ya que ha patentado el sabor único de su pasta para el cuidado dental, siendo un referente en otorgarle un valor agregado y diferencial a su producto estrella para generar un mayor sentido de pertenencia con su consumidor.

\section{Comunicación $360^{\circ}$}

Así, en este contexto de los sentidos y experiencias, es importante resaltar que las Relaciones Públicas deben cumplir un rol fundamental no solamente en su función de asesoramiento estratégico en la comunicación de las organizaciones con sus audiencias, sino también en la generación de contenidos y nuevas formas de acercamiento entre las marcas y sus actuales (y potenciales) consumidores.

Hoy la comunicación debe gestionarse desde lo que llamamos $360^{\circ}$, y la visión a largo plazo que ofrecen las Relaciones Públicas le permitirá a las marcas encontrar las mejores situaciones para encontrarse con sus consumidores, en un mundo de experiencias multisensoriales, claro está.

Edelman, es la firma de Relaciones Públicas independiente más grande del mundo. Recientemente anunció la creación de Brand Experience, una nueva práctica que tiene como objetivo crear experiencias multisensoriales que motiven al público a interactuar con las marcas.

La nueva práctica de Edelman está focalizada a brindar asesoramiento en acciones de marketing, publicidad, organización de eventos, diseño y producciones audiovisuales, gráficas y digitales.

Brand Experience -la nueva práctica- ya viene desarrollando diferentes acciones para distintos clientes de la firma, tales como Samsung, Staples, Manpower y Yamaha Motor, entre otros.

A nivel mundial, Brand Experience también cuenta con equipos especializados en las oficinas de Nueva York y Chicago, entre otras, desde donde brindan asesoramiento al resto de los países que conforman las 51 oficinas de la firma. A nivel mundial, Brand Experience también cuenta con equipos especializados en las oficinas de Nueva York y Chicago, entre otras, desde donde brindan asesoramiento al resto de los países que conforman las 51 oficinas de la firma. De esta forma, la oficina de Buenos Aires es la tercera oficina de la red en desarrollar esta práctica.

\section{Bibliografía}

Grunig, J. y Hunt, T. (1984). Managing Public Relations. New York: Holt, Rinehart and Winston. 
Summary: The present work approaches what is called today Multisensorial Communication, in which the creativity of human language acquires an even greater relevance as a generating vehicle of new contents to arrive at the consumer. The article describes the scenario where communication has been evolving to - scheme in which no longer the traditional models or channels are sufficient - with the aim of identifying opportunities, capitalizing benefits and to reach effectively the audiences in which companies want to position itself institutionally, or towards where the brands need to go in order to manage 'to sell' its products. The long term communication $360^{\circ}$ and vision that offer the public relations, will allow the brands to find the best situations to be with its consumers against this background of senses and experiences.

Key words: $360^{\circ}$ Communication - Brand Experience - communication plans - communicational management - Corporate Communication - Corporate Image - Customer Communications - Integrated Communications - Marketing Communications - Multisensorial Communication - Organization - public - Public Relations.

Resumo: O presente trabalho realiza uma abordagem do que hoje se denomina Comunicação Multisensorial, na qual a criatividade da linguagem humana adquire uma relevância ainda maior como veículo gerador de novos conteúdos por chegar ao consumidor. Descreve o palco para onde foi evoluindo a comunicação -esquema no que já não são suficientes os modelos nem os canais tradicionais- com o objetivo de identificar oportunidades, capitalizar benefícios e atingir de maneira efetiva às audiências nas quais as companhias querem posicionar-se institucionalmente, ou para onde as marcas precisam ir para conseguir 'vender' seus produtos. A comunicação $360^{\circ}$ e a visão a longo prazo que oferecem as relações públicas, permitirá às marcas achar as melhores situações para encontrar-se com seus consumidores neste contexto dos sentidos e experiências.

Palavras chave: Brand Experience - Comunicação 360 - Comunicação com os Clientes - comunicação corporativa Comunicação de Marketing - comunicação empresária - Comunicação Multisensorial - Comunicação os Consumidores - Comunicações Integradas - gestão comunicacional - imagem corporativa - organização - planos de comunicação públicos - Relações Públicas. 